\title{
O MUSEU CURADOR: APARECIMENTO, CONSERVAÇÃO E APAGAMENTO DA OBRA DE ARTE
}

\section{THE CURATOR-MUSEUM: APPEARANCE, CONSERVATION AND DISAPPEARANCE OF THE WORK OF ART}

Emerson Dionisio Gomes de Oliveira² 


\section{Resumo}

Nas últimas quatro décadas uma quantidade considerável de instituições museais, dispares em suas finalidades, voltaram-se para constituir narrativas que objetivaram propor sentidos a suas coleções e as formas de exibi-las. A hipótese central deste texto centra-se no museu curador como uma instituição capaz de produzir uma história da arte particular, nem sempre articulada com os cânones da disciplina e mais atenta às táticas e aos dispositivos de uma "cultura da curadoria". Para tanto, buscaremos debater, um conjunto ações-em-obra que expressaram pela cultura curatorial, a existência de uma produção artística deliberadamente criada, transformada e extinta para e dentro de instituições museológicas.

Palavras-chave: Museu de arte. Curadoria. Arte imaterial. Acervos.

\section{Abstract}

In the last four decades, a considerable amount of museal institutions with differing goals turned themselves to constituting narratives that aimed to propose a meaning to their collections and how they were displayed. The main hypothesis of this text is centered on the curator-museum as an institution capable of producing a particular Art History, not always articulating with this discipline's canon and more attentive to tactics and devices of a "curatorship culture". To such an end, we seek to debate a set of actions-in-artwork that expressed by the curatorial culture, the existence of an artistic production deliberately created, transformed and extinguished for and within museological institutions.

Keywords: Art museum. Curatorship. Immaterial art. Collections.

ISSN: 2175-2346

1 Este texto é resultado de pesquisa financiada pelo CNPq. 


\title{
1 Problema
}

Preocupada em apresentar a tensão existente entre o ateliê e o discurso expositivo, Véronique Rodriguez (2002) questiona o lugar e a origem da criação artística. Para tanto, ela toma a arte in situ, produzida na contemporaneidade no museu-galeria, como vetor da mudança e da desconstrução do ateliê privado burguês do "mestre", tão fortemente defendido no passado recente. Em seu diagnóstico, a partir de obras produzidas nos/e/ para os museus, espaço que nos interessa nesse artigo, Rodriguez sentencia: "não são mais as obras que transitam na caixa, com todos os riscos de danos imagináveis, mas o artista que passa de um lugar de exposição para outro, assumindo o controle" (2002, p.135, tradução nossa). Neste artigo buscamos nos filiar ao argumento da autora, mas em outra dimensão. Deixamos a relação ateliê e exposição para questionar a origem da obra de arte como problema. E, passemos a refletir como os artistas assumem o "controle" na relação entre expositividade-curadoria e (des) arquivamento, transformando e transtornando os protocolos museológicos atuais.

Para operar uma breve aproximação sobre uma questão ampla e raramente passível de generalizações, tomaremos obras de artistas brasileiros como ações provocadoras. Do mesmo modo, nos aproximamos de instituições museológicas ativas, que produzem e constroem redes e filiações entre a prática da arte contemporânea, seus espaços de visibilidade, seus projetos curatoriais e suas políticas de arquivamento. Ainda, na intenção de esclarecer a quais premissas nos associamos, tomemos a inversão ofertada pelo historiador da arte e curador Boris Groys, que toma o museu como espaço da realidade "viva", em contraposição a vulgar noção de museu "mausoléu" - extensivo a seus acervos -, enquanto um espaço exterior ao real, portanto, exterior a obra de arte "viva":

\begin{abstract}
Parece-me que os numerosos discursos sobre memória histórica e sua representação frequentemente negligenciam a relação complementar que existe entre realidade e museu. O museu não é secundário à história "real", e nem é meramente uma reflexão e registro do que "realmente aconteceu além de suas paredes conforme às leis autônomas do desenvolvimento histórico. O contrário é verdade: a "realidade", propriamente dita, é secundária em relação ao museu - o "real" somente pode ser definido em comparação com a coleção do museu. Isso significa que qualquer mudança na coleção do museu provoca uma mudança em nossa percepção da realidade como tal -, afinal de contas, a realidade pode ser definida nesse contexto como a soma de todas as coisas que ainda não são colecionadas. Logo, a história não pode ser compreendida como um processo totalmente autônomo que acontece além das paredes do museu. A imagem que fazemos da realidade depende de nosso conhecimento do museu (GROYS, 2015, p.39, grifo nosso).
\end{abstract}

Essa inversão é importante porque realinha as coleções de arte, pertencentes aos museus, como parte constitutiva do que definimos e chamamos de artístico para além dos sistemas de distinção e as teorias de institucionalização. Em sua especulação, Groys nos convida a pensar que muitas das obras modernas e contemporâneas só parecem estar na "realidade" quando expostas e acervadas nos museus. Retomaremos a provocação do historiador mais adiante. 


\section{0 de setembro de 2042: artista tático}

Mirante é um projeto encomendado pelo Museu da Universidade Federal do Pará em 2005 para se instalar no jardim do Palacete Augusto Montenegro (1903), cede da instituição [fig.1.]. Obra de Armando Queiroz, Mirante constituía-se de peças modulares de madeira no formato quadrangular com uma perspectiva interacional, pois sua forma aberta convidava o museu e seu público a dispor as peças em posições, condições e sequencias distintas. A princípio uma obra vertical que funcionasse como observatório diante do próprio edifício do museu, mas que foi sendo alterada ao logo dos anos seguintes (MORKAZEL apud QUEIROZ, 2010). A encomenda estava vinculada ao projeto "Jardim das Esculturas" do museu, cuja finalidade era compor uma mostra de longa duração com esculturas e/ou intervenções no jardim da instituição e contava, na época, com a participação de outros quatro artistas.

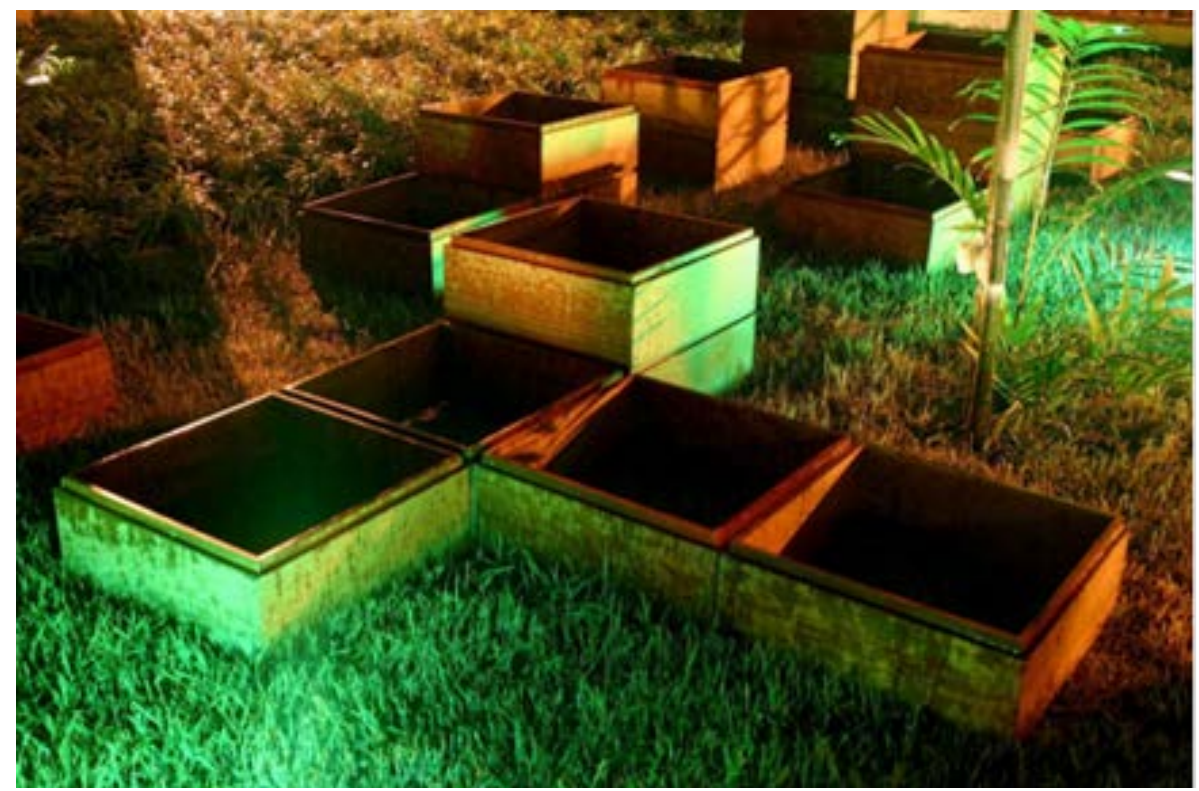

Fig. 1 - Armando Queiroz, Mirante, 2005-2006, objeto-escultura; acervo do Museu da Universidade Federal do Pará. Foto do artista. Fonte: BRITO, 2016.

Queiroz é uma referência da arte contemporânea paraense. Dedicado à produção conceitual, atua como instalador, escultor, fotografo, performer, videoartista, entre tantas linguagens que ele suscita para produzir uma obra vinculada às questões políticas do cotidiano e devotada a criticar uma visão mistificadora do território amazônico. Dando especial ênfase às contingências que marcam a história da região como uma história de violências; uma produção compreendida entre o onírico, um estado mágico e a dureza do "real", num entrelace entre arte e história, como avalia a curadora Mariza Morkazel (apud QUEIROZ et. all.,2010, p.50).

Nos anos subsequentes, Mirante transitou entre as áreas expositivas internas e externas do museu, até que em 2010, estimulado pela instituição a restaurar a obra, o artista decide eliminá-la, enterrando-a. Rapidamente a instituição assimilou a provocação de Queiroz, que propunha a ação performática denominada Desapego [fig.2]. Uma nova obra que consistia no enterro de Mirante no mesmo jardim das esculturas. Do trabalho só restaria uma placa-lâpide no local. Mirante, uma obra acervada agora passava por um novo estado de agencia. Uma nova forma de compreender sua existência material, passava pela "imaterialidade" de Desapego. 


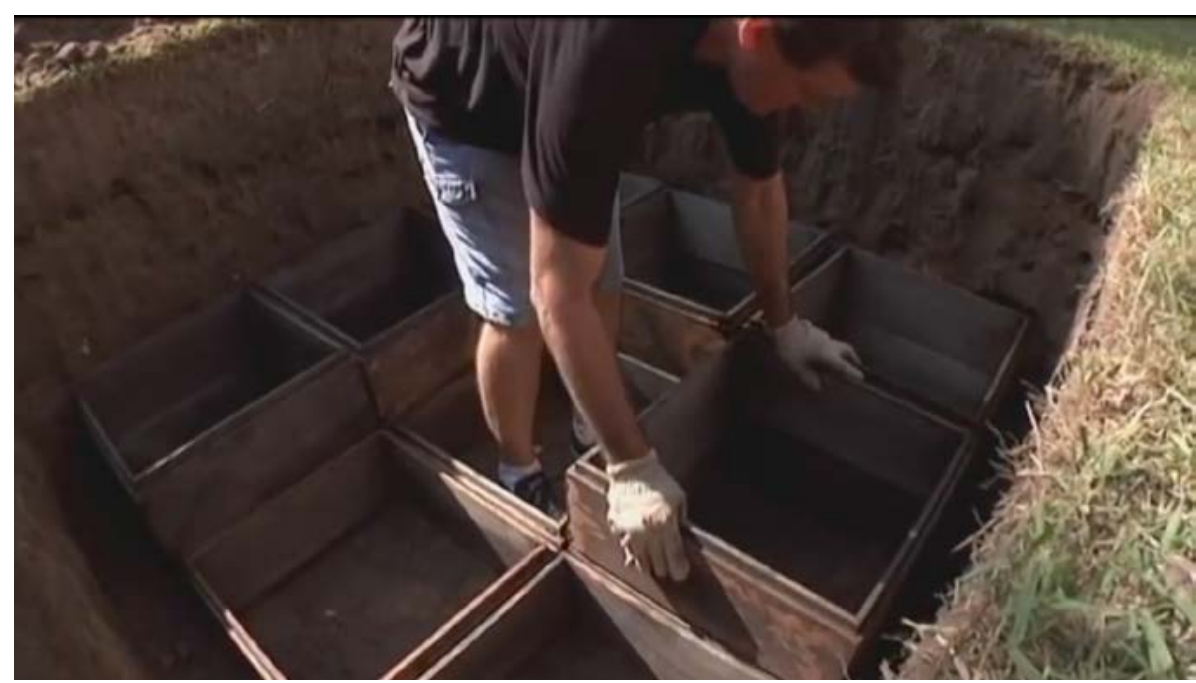

Fig. 2 - Armando Queiroz, Desapego, ação (frames do vídeo homonômico), 2010. MUFPA.

Se hoje vemos a institucionalização de obras que no passado suscitavam questionamentos sobre o fetiche do trabalho artístico, do lugar social do artista e, mesmo, da história da arte, como nos enterros produzidos por Keith Arnatt (Auto enterro, nove fotografias televisionadas pertencentes ao acervo da Tate) em 1969, e por Daniel Spoerri, em 1983 (Funeral do Almoço na relva, em 23 de abril de 1983: 120 personalidades do mundo da arte contemporânea, do acervo Institut Nacional de Recherches Archéologiques préventives), Desapego parece inscrever um peculiar capítulo entre as obras e as instituições museológicas no Brasil.

Já Balaústre pode ser tipificado como site-specific [fig.3]. A artista Ana Ruas a qualificou como uma intervenção na nova sede do Museu de Arte Contemporânea do Mato Grosso do Sul (MARCO), em 2004. Ruas pintou na rampa, que une o primeiro e o segundo pisos do museu, uma cadeia de balaústres, num jogo perspectivo de sombras que conferia dinâmica e movimento à aplicação. A artista escolheu o "balaústre" graças a sua presença marcante na Morada Lídia Baís, espaço museológico que celebra a memória e a história da, então, considerada fundadora da arte moderna no Mato Grosso do Sul, a pintora Lídia Bais. Transformando uma rampa numa escada, o elemento arquitetônico tornou-se para Ruas o elo entre as duas instituições culturais, celebrando a seu modo uma metonímica entre os espaços e suas memórias ${ }^{1}$. Entre o pioneirismo de Bais e a produção hodierna.

1 Entrevista com a Artista Ana Ruas em 10 de junho de 2015, em Campo Grande-MS, para o projeto "Registro e reapresentação dos acervos de arte brasileiros: análise compartativa" (2013-2016), financiado pelo CNPq. 


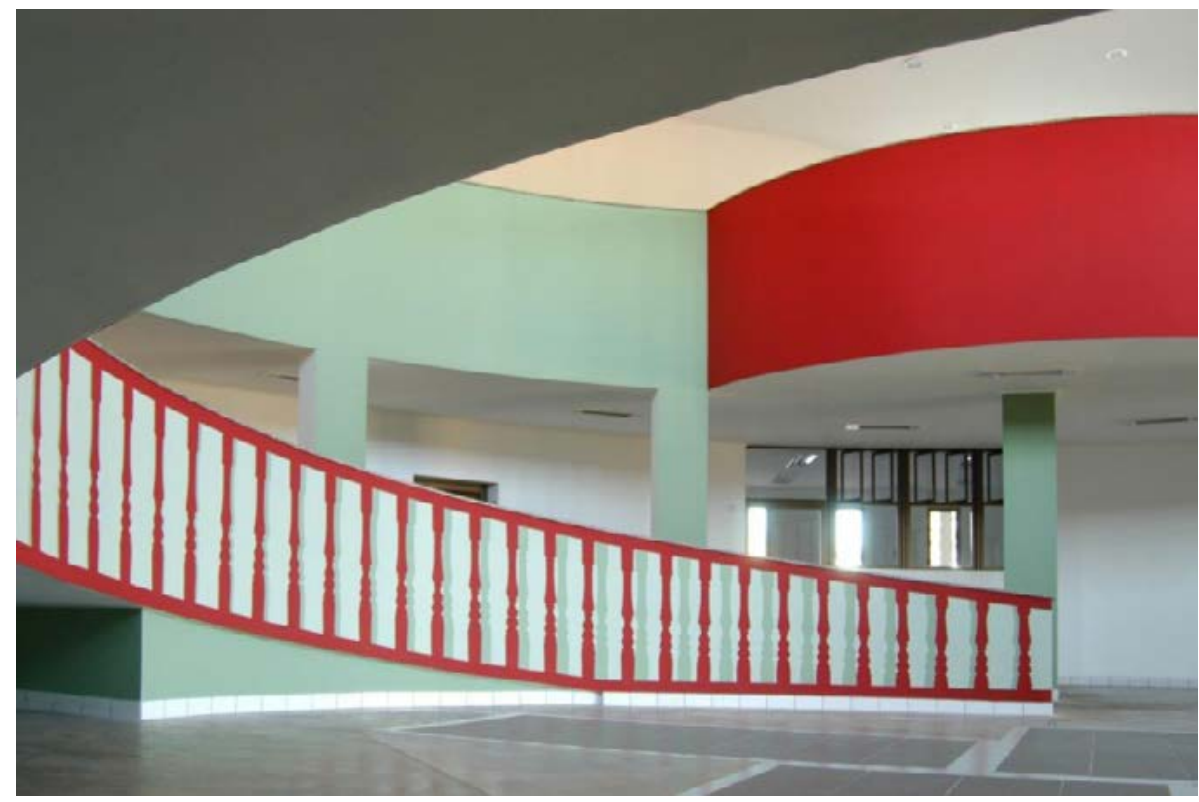

Fig. 3 - Ana Ruas, Balaústre, 2004, MARCO, Campo Grande, MS. Fonte: <http://anaruas.com.br/obras>

Do mesmo modo que Queiroz, Ruas é uma referência da produção contemporânea em seu Estado. Nas últimas duas décadas se dedicou a produzir obras destinadas à ocupação e à transformação do espaço urbano e museológico. Do mesmo modo, sua compreensão do elemento arquitetônico, seja na acepção convencional, seja na amplitude da condição urbana, apresenta o estranhamento e a suspensão do cotidiano habitado. Obras como Projeção, de 2008, no viaduto Pedro Chaves em Campo Grande, ou Colunas, de 2009, na Pinacoteca da Universidade Federal de Alagoas, expressavam a ambiguidade das imagens, um jogo de perspectivas e espelhamentos similares a Balaústre e a Plano $B$ de $2014^{2}$. Aliás, foi justamente no momento em que Plano $B$ surge como um novo site-specific no MARCO, num novo diálogo com a arquitetura e o espaço do museu, que a presença de Balaustre é coloca em questão.
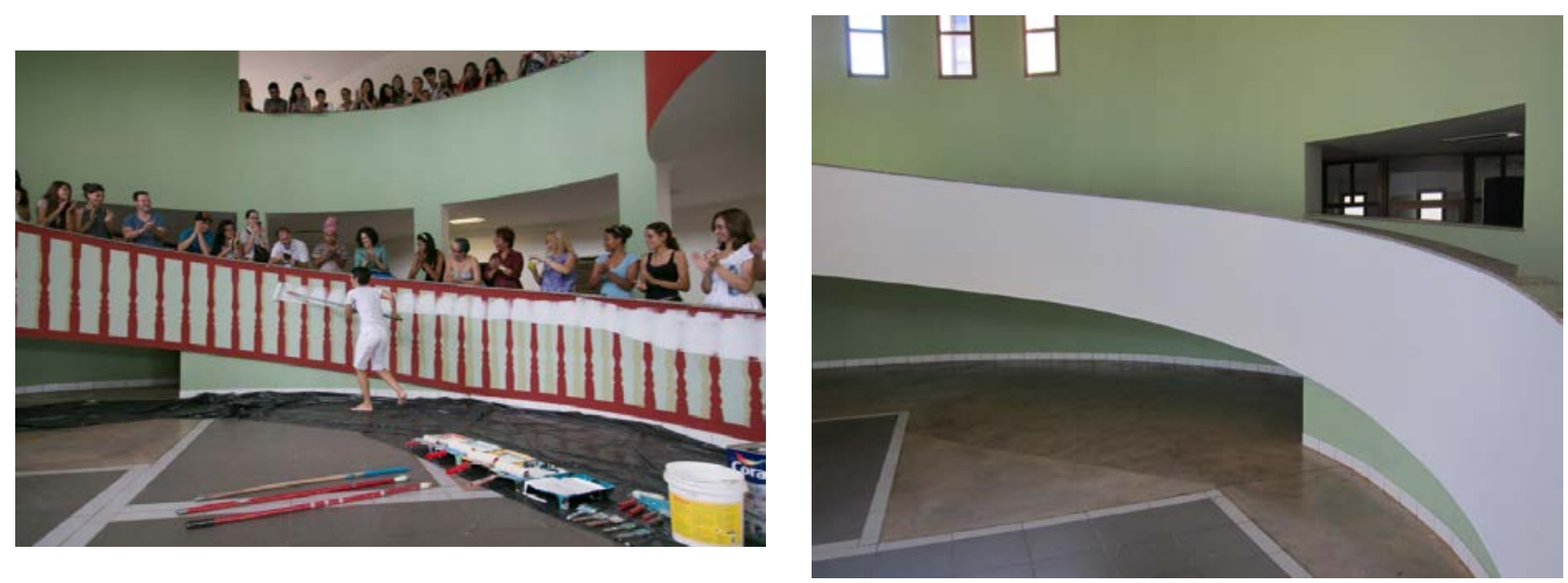

Fig. 4 e 5 -Ana Ruas, Apagamento, 2014, MARCO, Campo Grande, MS. Fonte: <http://anaruas.com.br/obras>

Uma obra concebida para ser "efêmera", com duração de poucos meses, habitava o museu há dez anos. Diante do dilema de como preservar o site, Ruas decidiu 
apagar a intervenção de 2004. Do mesmo modo que Queiroz, a artista evoca uma ação performática, neste caso denominada Apagamento [figs.4-5]. Em entrevista, a autora lembra que convidou duas centenas de pessoas para participar do processo de destruição da obra, segunda ela "Apagamento criou um estranhamento e um suspense incrível. Na hora seguinte, o vazio, o silêncio e o branco deram margens à discussão sobre a ausência dos balaústres. Penso que a obra ganhou ainda mais força" (RUAS, 2014, p.317). Tomemos como exemplo uma terceira obra.
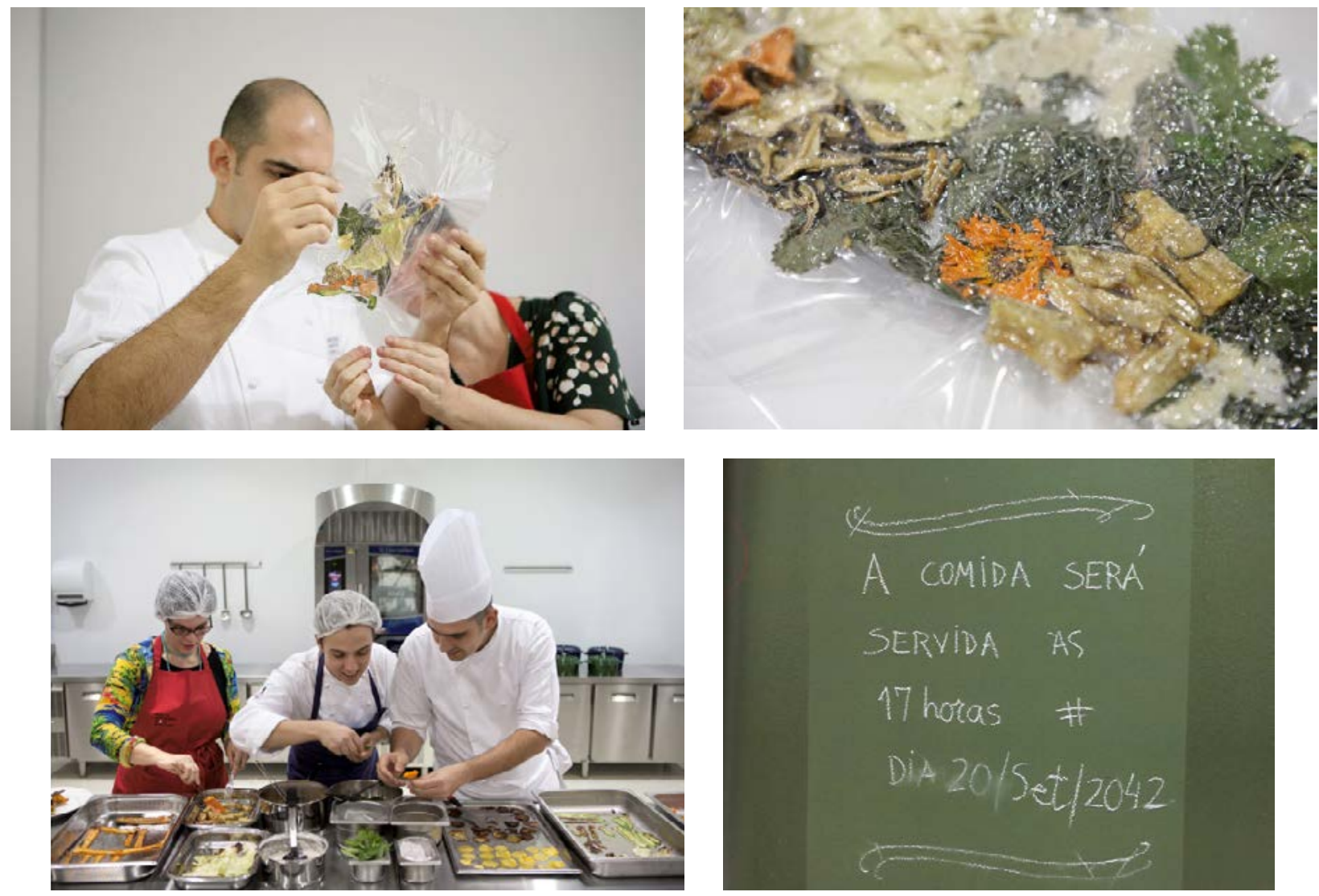

Fig. 6 a 9 - Laura Lima e José Barattino, Comida, 2012. Encontros de arte e gastronomia, MAM SP. Foto: Edouard Fraipont. Cortesia da artista.

Comida é uma ação realizada pela artista Laura Lima, em parceria com o chef de cozinha José Barattino. A parceria para a constituição do prato/obra foi provocada pelo projeto "Encontros de arte e gastronomia", do Museu de Arte de São Paulo, em 2012, com curadoria de Felipe Chaimovich e o chefe Laurent Suaudeau. O princípio do projeto era unir artistas contemporâneos com chefes. De um lado nomes como: Amanda Lopes, Tsuyoshi Murakami, Ana Luisa Trajano, Philippe Brye, entre outros; do outro: Regina Silveira, Caetano Dias, Rochelli Costi, o Coletivo Opavivará, etc.. Todos reunidos para produzir ações que conciliavam gastronomia e artes visuais. Comida fora uma das ações que mobilizou Barattino e Lima. De fato, a artista brasileira é uma das referências quando o assunto é associar práticas visuais e outros sentidos. Gelatina (1996), Jantar mudo (1999) e Faisões com comida (2005) são obras distintas que lidam com o alimento enquanto matéria em trânsito, em transformação.

Em especial Comida incorpora o arquivamento ao produzir alimentos que serão consumidos em 2042. Essa é a questão-provocação: cozinhar e empacotar a vácuo 
um jantar que será servido às 17 horas do dia 20 de setembro de 2042. Comida cria, assim, uma (im) possibilidade, uma promessa, portanto, uma suspensão temporal guiada pelo arquivamento. "A dupla pesquisou alimentos que pudessem ser desidratados e embalados a vácuo para atingir uma data de validade substancial" (CASTRO; LAGNADO, 2014, p.246). A obra (projetar, planejar, selecionar, cozinhar, embalar, guardar, servir, consumir etc.) foi doada ao Museu de Arte Moderna de São Paulo, então proponente da ação e seu gestor. Desta forma, o acervamento tornou-se chave da provocação. A seu modo, Lima testa a longevidade da instituição, sua capacidade de avaliar, assimilar e salvaguardar a ação-produto. Testa, enfim, o sentido de "excepcionalidade" da obra de arte, dilatando seu efeito. Transforma a instituição em chave para o processo de compreensão, manutenção e acionamento da obra. Por último, define o dia do fim da obra, enquanto processo material.

Tomado em seu conjunto os trabalhos de Lima, Queiroz e Ruas são inflexões táticas dentro das instituições. A supressão, a extinção e o arquivamento são tomados como posições que inscrevem narrativas próprias, transformando cada proposição numa ação para além do tempo estratégico operado inicialmente pelos artistas. $O$ jogo é duplo, o museu instiga e convida à ação, mas é, simultaneamente, tomado de assalto por ela. Lembremos que "a tática não tem por lugar senão o do outro. $\mathrm{E}$ por isso deve jogar com o terreno que the é imposto tal como o organiza a lei de uma força estranha" (CERTEAU, 1994, p.100)3. Nesse sentido, cada uma das obras não apenas expõem o museu como contexto, mas apresenta-o como cumplice, articulador, curador.

Os trabalhos evidentemente não podem ser calculados como simples críticas às instituições. Parece-nos um tanto distante o tempo em que artistas contemporâneos rejeitavam veementemente os espaços museológicos como lugares legítimos para visibilidade de suas obras. Assim, museus, galerias, centro culturais e uma miríade de novas modalidades expositivas assimilaram as críticas a eles dirigidas desde os anos de 1960. De indesejáveis, tais instituições tornaram-se "indispensáveis" nas palavras de Anne Cauquelin (2008, p.69), alterando sua correlação com a produção artística: de mediadores entre a produção e um público, mais ou menos genérico, passaram eles mesmos a conduzir a crítica, antecipando-se, por vezes, ao "esvaziamento" de sentidos pretendido pelos artistas. Certamente, é tentador tecer elogios à capacidade operacional das instituições museológicas frente às experimentações das últimas seis décadas, mas, a seu modo, o museu permaneceu fiel a sua trajetória narrativa desde os oitocentos. Cito Belting: "Os museus de arte, no passado, não estavam apenas exibindo arte, mas estavam narrando a história da arte ou apresentando arte no espelho de sua própria história". Ou seja, como entidade que opera a partir das "forças de narcisação" ${ }^{4}$, museus buscaram instituir-se como ponto de partida e chegada da produção artística, articulando diferentes dispositivos, discursos e projetos políticos.

\footnotetext{
3 E continua, a tática: "Não tem meios para se manter em si mesma, à distância, numa posição recuada, de previsão e de convocação própria: a tática é movimento 'dentro do campo do inimigo', como dizia Von Büllow, e no espaço por ele controlado. (...) Ela opera golpe por golpe, lance por lance. Aproveita as 'ocasiões' e delas depende, sem base para estocar benefícios, aumentar a propriedade e prever saídas. O que ela ganha não se conserva" (idem, p.100, grifo nosso). 
Tais "forças de narcisação" poderiam induzir uma tese geral sobre o comportamento das instituições de arte frente a produção artística correlata, em diferentes frentes. Como, por exemplo, pensar como tais instituições de arte operaram como coprodutoras da arte contemporânea, associando-se aos antigos regimes da encomenda e do mecenato. Imaginá-las como sítio para o desenvolvimento de projetos que as tomam como parte componente da obra, tanto em sua dimensão operacional, quanto simbólica. Apresentá-las como mantenedoras de narrativas biográficas em franco atendimento a uma história da arte teleológica e autoindulgente. Percebe-las como "lugares na memória", a partir de práticas de acionamento dentro de políticas urbanas localizadas. Criticá-las em suas táticas autorreferentes, de autopreservação institucional, preocupadas em instruir não uma experiência da arte, mas uma experiência com a arte. Apontá-las como pretensas produtoras, aptas a gerar um campo "bioestético", "capaz de captar a totalidade da experiência estética" (BRAZ, 2016, p.09). Entendê-las dentro de sua condição performativa, ou seja, capazes de negociar antigas relações e hierarquias de poder ${ }^{5}$. Enfim, uma série de posições podem ser ofertadas. Todavia, optamos por refletir no museu como curador.

De certo, seria difícil debater as diferentes frentes e as possibilidades a que entendemos como "curadoria" na atualidade. O que foge a competência deste artigo. Preferimos compreendê-la em sua dimensão operacional e seu contato com um fazer da história da arte contemporânea. Sabedores do quão artificial é o apartamento dos demais sentidos que o conceito de "curadoria" tomou e toma no presente, nos é preferivel atentar para o sentido de uma "cultura da curadoria" coligada pelo e no museu. Tal cultura é responsável pela articulação dos significados que permeiam à arte na maioria das instituições museológicas da atualidade. Seria, então, uma cultura das estratégias cênicas e discursivas que funcionam como elo entre tantas outras estratégias narrativas. Em sua ética basal, tal cultura, ao menos no que se predica, seria capaz de garantir a integridade poética das obras e sua relação com a história, às táticas expológicas, às nuances do mercado e todos os demais agentes do sistema que se relacionam com o museu.

Sendo assim, a curadoria funciona a partir de dispositivos que não terminam nem começam naquilo que classicamente chamamos "projeto curatorial", preocupado a priori com um discurso unificador, modelando expografias, narrativas historiadoras, pedagogias mediadoras e representações midiáticas. Antes, a cultura curatorial seria extensiva a todo sistema das artes. Para além do design expositivo, ela tornou-se, em parte, uma força organizadora que empresta, sugere e, as vezes impõem, sua ética selecionadora, confeccionando discursos autorizados que estão, atualmente, baralhados às narrativas da história e da crítica de arte especializadas (SIQUEIRA, 2015). Nesse tocante, nos parece razoável conceber que não há parte do sistema das artes que não demonstre afinidade com tal cultura, incluindo nosso problema: uma "arte de museu"; a instituição museológica na organização de seus acervos; a prática expositiva; na definição de políticas de relacionamento com os artistas, com o mercado da arte e outras instituições patrimoniais. Sendo assim, a questão que se abre

5 Para o historiador indiano Dipesh Chakrabarty, a condição performativa do museu dá-se quando a instituição abandona a relação hierarquizada de poder: daquele que tudo sabe, tudo guarda e tudo ensina para a condição que reconhece a capacidade agentiva do público; abandonando a noção de um espectador abstrato, incapaz de possuir conhecimento, experiência e memória prévios. 
é como o museu, articulado na e pela "cultura da curadoria", impacta nas narrativas da arte que recebe, expõe e coleciona? Como uma história da arte se articula nessa conjectura? De fato, se levarmos em conta que o problema aqui é o museu dedicado à arte contemporânea, qualquer resposta é demasiadamente provisória. Mas antes de tentar qualquer resposta, é preciso compreender os pressupostos das questões. Três deles nos orientam. Primeiro a dimensão heterocrônica do museu. Segundo, a obsessão documentária do museu e seu uso da História da Arte para constituir continuidades. E por fim, a condição agentiva da instituição.

A capacidade heterocrônica do museu recebeu atenção de pensadores de diferentes áreas. Tomemos a perspectiva pontuada por Belting:

Entre os lugares alternativos ou 'heterotopias' que a modernidade produziu,
conta-se o museu. Tal como os cemitérios - escreve Foucault -, as heteroto-
pias 'estavam, com frequência, ligadas a cesuras temporais, ou seja, abriam-se
ao que poderíamos designar, simetricamente, de heterocronia; a heterotopia
passa a funcionar em pleno quando os homens se encontram como que em
ruptura total relativamente ao seu tempo tradicional'. Pertencem a uma época
e criam um lugar fora do tempo em que a vida transcorria. Ao excluírem-se do
tempo corrente, tais lugares podem transformar o tempo numa imagem e
recordá-lo mediante uma imagem. A permuta entre lugar e imagem, de que
aqui se fala, também se observa na instituição museu. Este é não só um lugar
para a arte, mas igualmente um lugar para coisas já sem uso, para as imagens
que representam outra época e se tornam, assim, símbolos da memória. Elas
não só reproduzem lugares no mundo, como noutra época foram compreen-
didos, mas são em si mesmas formas histórico-mediais, porque veiculam uma
compreensão imaginal do passado. No museu trocamos o actual mundo da
vida por um lugar que captamos e vemos como imagem de outro lugar muito
diferente. Nele contemplamos obras que concebemos como imagens que
foram pintadas para outra época, como imagens que só no museu possuem
o seu lugar." (BELTING, 2014, p.92-93, grifo nosso).

Com o aparecimento de obras que não mais reivindicam uma presença diante de nossos olhos, como as pinturas de outras épocas que nos alcançaram, mas que fundam um "discurso da presença", pois são recorrentemente obras em perpetua reconstrução, reapresentação; readaptação. Uma obra em diferentes versões (OLIVEIRA, 2015). Tal conjunto de obras realinha uma história da arte diante de uma história da apresentação da arte. Ou seja, o museu está diante de obras que não mais expressam apenas um passado re-significado, mas instauram uma potente expectativa do devir. Assim, a dimensão heterocrônica do museu ganha novo horizonte diante de obras que não mais existem em suas reservas técnicas, nem em outro lugar qualquer, mas são instrutivamente dependentes da negociação entre distintos narradores e "manipuladores" de imagens e representações.

Essa contingência da obra que se encontra no "passado-futuro" tem aguçado a obsessão documentária das instituições museológicas. Elisa Noronha Nascimento (2014) lembra-nos que os museus de arte contemporânea operam numa circularidade, pois reinventam-se na medida que musealizam a arte que desejam colecionar e expor; a arte a qual estão identificados. Assim, quanto mais dependente for a arte de sua lógica operadora, mas bem quista esta será para a instituição. No museu, o 
registro da obra passa pelo registro de si.

Há alguns anos, Anne Cauquelin refletia que "a galeria ou o museu permanecem como o pivô do movimento de exportação das obras e recolhem piedosamente as pistas documentadas do exílio" (2008, p.68), as obras lhe eram exteriores; hoje, as obras parecem continuamente a "renascer" dentro do museu e a partir dele. Nada novo a princípio uma vez que Jean-Marc Poinsot reclama que é essa a própria condição do museu de arte no ocidente: a capacidade de expor e colecionar objetos que chamamos de "arte", mas que uma vez no museu, preservam, contra os ataques alheios, sua dimensão estética. $O$ que temos, nas últimas décadas, é uma arte que nasce como demanda do museu. Levando o crítico David Carrier, em seu instrutivo "The Contemporaty Art Gallery: Displey, Power and Privilege" (2016), a se perguntar se no futuro não seria melhor chamar a arte contemporânea de "arte da galeria contemporânea"? Na avaliação de Peter Scheenemann (2017), a história do museu de arte é a história de uma instituição que expõe arte como condição auto referencial, o problema é quando o museu se esquiva, enquanto agente cultural, da qualidade auto reflexiva.

Eis nosso último pressuposto: a condição agentiva do museu. Na mesma direção de Rodriguez, Martha Buskirk (2003) aponta que uma das características do museu de arte contemporânea é que ele embaralhou o eixo artista-obra/ateliê-museu. Independente das linguagens e suportes adotados e graças as tramas narrativas, as instituições museológicas tornaram-se parte do ateliê do artista, passaram a ser um "pressuposto" de boa parte da arte produzida nas últimas décadas. Neste cálculo soma-se a autoridade crescente da cultura curatorial na organização das narrativas museais. Para Boris Groys (2008), a dissipação da autoria entre artistas e curadores alcançou de algum modo as instituições. Para ele, os papéis, que no passado, organizavam quem decidia qual a relação entre a produção no ateliê e a exposição na instituição não são mais claros. Quanto mais complexa se tornou a "trajetória" de uma obra, mais sujeitos tem participado das negociações que definem como um trabalho em arte será apresentado e narrado; em última instância, como a obra se relaciona com suas pares contemporâneas, com suas antecedentes e como, na chave das expectativas, ele poderá dialogar com futuros trabalhos de arte.

\section{Considerações sobre o fim}

Artur Danto já advogava, nos anos de 1980, que existia uma "forma de arte emergente que usa o museu como repositório" (2006, p.7). Com cuidado, podemos inverter sua premissa ao dizer que existe uma forma de museu emergente que usa a arte como repositório. Nesse tocante, Mirante/Desapego; Balaustre/Apagamento, Comida e inúmeras outras obras expressam, pela cultura curatorial, a existência de uma produção artística deliberadamente criada, transformada e extinta para e dentro de instituições museológicas. Mas o sentido de extinção, de desaparecimento, de ocultação não pode ser confundido com o mero esquecimento. Seja na dimensão de um "esquecimento de reserva" ou de um "esquecimento feliz", nas acepções de Ricoeur (2007). Queiroz, Ruas e Lima são conscientes dos operadores ofertados pelas instituições, ao propor a mutação, a transformação e a rememoração de suas obras; eles restituem ao museu 
sua capacidade mnemônica: um contínuo jogo de narrativas (ativações) e supressões (apagamentos). Assim pelo silêncio Desapego constrói uma memória de Mirante, pelo vazio Apagamento reinscreve Balaustre na arquitetura entre-instituições e por meio da lembrança-expectativa de Comida vigiamos o museu até 2042.

Assim, voltemos ao pressuposto de Groys que afirma o museu como lugar da contradição do real, "como uma instituição que tem a missão de representar as diferenças" e que "também pode cria-las" (2015, p.51). Esta é a conjugação entre o museu-conservação e o museu-curador. Segundo o historiador para produzir novas diferenças, o que para ele significa o "novo" na arte atual, necessitamos de um espaço de "não-realidade", culturalmente codificado e reconhecido (idem, p.46). As obras que se ocultam dentro e para d/o museu são capazes de devolver aos artistas o controle, de orientá-los na transformação e no esgotamento de seus trabalhos. Assim, se acreditássemos que há uma única maneira de produzir a "história da arte" dentro das instituições, seriamos tentados a compreendê-la como aligeirada desse processo. Mas a inversão anterior nos oferta a possibilidade de compreender qual impacto desta "cultura da curadoria", dentro do museu, para a constituição de uma nova - diferente - história da arte. Uma história da arte pública e visível para um público cada vez mais amplo e diverso. Uma história da arte que compreende e se posiciona diante da perspectiva autorreferente do museu; que problematiza os jogos políticos operados pelos artistas e pelas instituições em suas, não mais sutis, políticas curatoriais. Diante do museu, uma história da arte que proponha o diálogo sobre obras capazes de "transformar o tempo numa imagem" e recordá-las mediante outras imagens (BELTING, op.cit.).

\section{Referências}

BELTING, Hans. Antropologia da Imagem. Para uma ciência da imagem. Lisboa: KKYM; Escola de Arquitetura da Universidade do Minho, 2014, p.92-93.

BRAZ, I. O que exatamente torna os museu de hoje tão diferentes, tão atraentes?, MIDAS. Museus e Estudos Interdisciplinares, nำ 6, 2016.

BRITTO, R. "Museu da Universidade Federal do Pará. Atribuição de valores ao patrimônio histórico musealizado". 1 Simpósio Cientifico ICOMOS Brasil. Belo Horizonte: ICOMOS, 2017. Disponível em: <https://even3storage.blob.core.windows.net/ anais/60336.pdf>. Acesso: dezembro de 2017.

BRITTO, R. "Museu da Universidade Federal do Pará: a paisagem museológica da "esquina" e a historicidade do lugar, de residência a museu universitário (1903-2015)". Anais do 15 Seminário Nacional de História da Ciência e da Tecnologia. Florianópolis: Sociedade Brasileira de História da Ciência, 2016, p.1-17.

BUSKIRK, Martha. The contingent object of contemporary art. Cambridge, MA: MIT Press, 2003. 
CARRIER, D.; JONES, D. The Contemporaty Art Gallery: Display, Power and Privilege. Cambridge, MA: CSP, 2016.

CASTRO, D.; LAGNADO, L (org)s. Laura Lima on_off. Rio de Janeiro: Cobogó, 2014.

CAUQUELIN, Anne. Frequentar os incorporais: contribuição a uma teoria da arte contemporânea. São Paulo: Martins Fontes, 2008.

CERTEAU, Michael. A invenção do cotidiano: artes de fazer. Trad. Ephraim Ferreira Alves. Petrópolis: Vozes, 1994.

DANTO, A. "Introdução: moderno, pós-moderno e contemporâneo" In:

Após o fim da arte. A arte contemporânea e os limites da história. São Paulo: Odysseus Editora, 2006.

ESPERANDIO, Mary Rute Gomes. Narcisismo reativo e experiência religiosa contemporânea: culpa substituída pela vergonha?, Psicologia e Sociedade, Porto Alegre, v. 19, n. 2, p. 89-94, ago. 2007. Disponível em: http://www.scielo.br/scielo.php?scrip$\mathrm{t}=$ sci_arttext\&pid=S0102-71822007000200012\&lng=pt\&nrm=iso; Acesso em 03 de outubro de 2017.

GROYS, Boris. "Multiple Authorship", in GROYS, Art Power. Cambridge, MA; MIT Press, 2008, p.93-100.

GROYS, B. Arte, Poder. Introdução. Trad. Virgínia Starling. Belo Horizonte: Editora UFMG, 2015.

NORONHA, Elisa. A musealização da arte contemporânea como um processo discursivo e reflexivo de reinvenção do museu, MIDAS, n³, 2014. Disponível em: http:// midas.revues.org/563; Acesso em 26 de setembro de 2017.

OLIVEIRA, E.D. "Regimes de exibição da arte contemporânea: instalação, reapresentação e registro" In: KNAUSS, P.; MALTA, M. Objetos do olhar: história e arte. São Paulo, Rafael Copetti Editor, 2015.

POINSOT, J. M. "A arte exposta: o advento da obra". In: HUCHET, S. (Org.). Fragmentos de uma teoria da arte. São Paulo: Edusp, 2012.

QUEIROZ, A.; MAIORANA, R.; SIQUEIRA, D.; et all (orgs.). Arte Pará. 29ạ edição: Armando Queiroz. Fundação Romulo Maiorana: Belém, 2010.

RICOEUR, Paul. A memória, a história, o esquecimento. Tradução Alain François [et al.]. Campinas: Editora da Unicamp, 2007. 
RODRIGUEZ, V. L'atelier et l'exposition, deux espaces em tension entre l'origine et la diffusion de l'oeuvre, Sociologie et Sociétés, no 342, 2002, p.121-138.

RUAS, A. Ana Ruas. Capa. Entrevista com Emerson Dionisio G. Oliveira, Revista Museologia e Interdisciplinaridade, vol. 4, no7, mar-abr 2014, p.316-319.

SCHNEEMANN, P. Remembering the presence. Possible roles of the Museum of Contemporary art today. In: Museologia e Interdisciplinaridade, vol.6, n12, jul-dez 2017. Disponível em: <http://periodicos.unb.br/index.php/museologia/article/ view/26815>. Acesso em 03 de outubro de 2017.

SIQUEIRA, V. B. C. "Curadoria como tarefa crítica". Anais do 24 Encontro da Anpap. Santa Maria, RS: Anpap, 2015, p.3896-3902. 